\title{
The BMH Dharan Silver Jubilee Symposium
}

\author{
Lieutenant Colonel G E Ratcliffe, \\ MB MRCP RAMC \\ Senior Medical Officer and Consultant Physician BMH Dharan, Nepal
}

BMH Dharan (Figures 1-4) was built in the late 1950's as an integral part of Dharan Cantonment in East Nepal, to provide medical aid for all British personnel and their families, Gurkha personnel and their families in Dharan, for the locally employed civilians in the Cantonment and for Gurkhas returning for or from leave. Its other main function has been to provide facilities each year for the medical examination of potential Gurkha recruits.

Since the hospital opened, however, it has developed a reputation for treating many other sick and needy people in East Nepal, an area where medical facilities are not well developed. Succeeding members of staff have over the past twenty-five years put in many hours of hard work to build a very enviable reputation. To celebrate its Silver Jubilee, a symposium was held to which guests from various medical organisations were invited to speak in an attempt to keep in perspective the work of the hospital.

\section{The Golden Throat}

After a few introductory remarks from the SMO welcoming members of staff and guests alike, the programme opened with a videotape, 'The Golden Throat', kindly donated by UNICEF in Kathmandu. This demonstrated the incidence of endemic goitre in Tuli Besi, a small village in the Mustang area of Nepal, and the attempts made by UNICEF in co-operation with the Nepalese Government Medical Authoritics to reduce this incidence by injecting iodised oil into all members of the local population. Nepal has a major lack of iodine in its soil, particularly in the mountainous, less accessible regions of the country. Such injections hopefully will provide sufficient iodine for normal metabolism for 5 years, and their use, particularly in young adults, should reduce the incidence of cretinism to a much lower rate.

Incidentally, 'The Golden Throat' refers to the reply given by one of the ladies in the area under investigation who, when asked what she thought was in her goitre, replied "Gold".

\section{Medical Organisation in Nepal}

Dr K R Pandey, the Civil Surgeon from the Koshi Anchal Hospital, Biratnagar, spoke about His Majesty's Department of Health programme for Nepal. The country is divided into Zones (Anchals) in the main centres of which are large Zonal Hospitals of 150-200 beds each, with smaller district hospitals elsewhere in the zonc, reducing in size to the basic unit, the health post, in the periphery and for the most part, in very inaccessible parts of the country. The health posts are run by health assistants and auxiliary health workers under the control of community leaders.

The life expectancy in Nepal is 44.5 years, and Dr Pandey described the importance of educating the various ethnic groups throughout the country in basic health techniques. This was of particular relevance in trying to reduce the infant mortality rate, for which safe water and sanitation programmes are in progress.

Because of various homeopathic and faith-healing techniques in use throughout the country, there was a certain amount of scepticism by the local population about the introduction of Western medical tcchniques. Progress tended to be slow therefore, although programmes are in hand to control tuberculosis, leprosy, gastroenteritis, etc, using immunisation and basi medical education. Similarly a major family planning programme is in progress.

\section{Dharan Educational and Medical Training Scheme (DEMTS)}

This programme was set up under the auspices of the Overseas Development Agency to teach various skile to ex-servicemen of the Brigade of Gurkhas. The medical training is organised by Dr B P Gurung who described the present system of up to two years' training depending on previously obtained educational qualifications.

This scheme is now accepted by the Institute of Medicine in the Tribhuwan University in Kathmandu as an alternative training for auxiliary health workers in Nepal. The DEMTS training programme produces 20 $25 \%$ of the trained auxiliary health workers in Nepal. In the first year instruction in basic anatomy and physiology is given together with teaching of health administration, sanitation and immunisation. Practical experience is gained in community surveys, in water purification, drug dispensing, laboratory techniques, and in maternal and child health. Some time is spent in the Zonal Hospital in Biratnagar as well as the BMH in Dharan, and since 1979 one hundred and eleven students have successfully completed their training,

\section{Medical Education in Tribhuwan University Medical School}

Dr J Dickinson, Medical Supcrintendent of Patan Hospital, Kathmandu discussed the founding of the Medical School in Kathmandu. This was set up with the help of the World Health Organization in the late 1970s and the first thirty Nepalese trained doctors qualified in 1984 followed by a similar number in 1985 . 


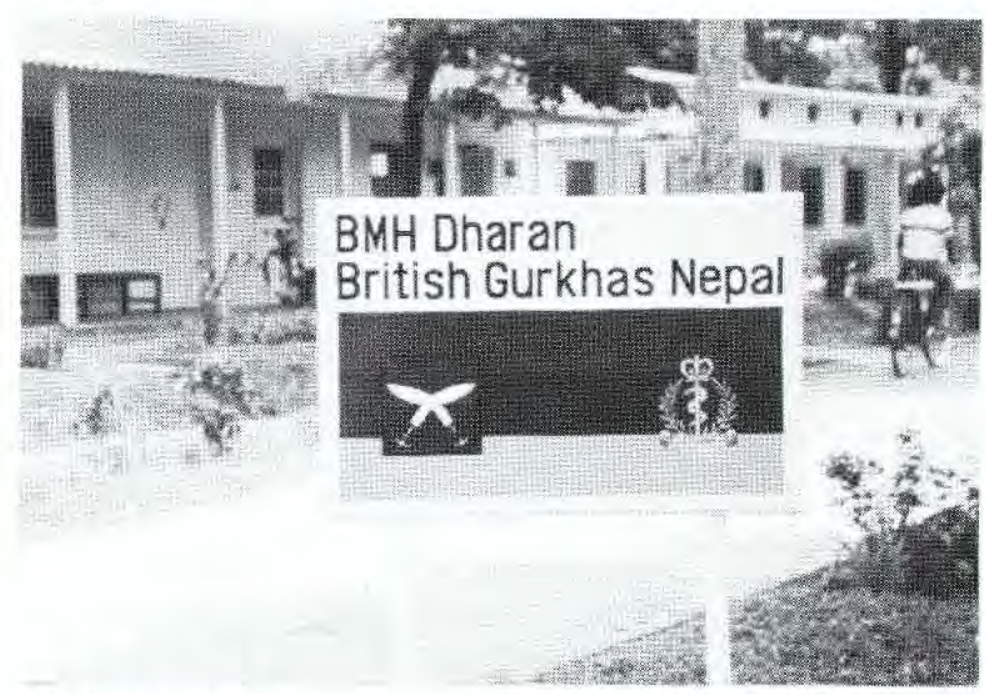

Fig. 1. Hospital Sign

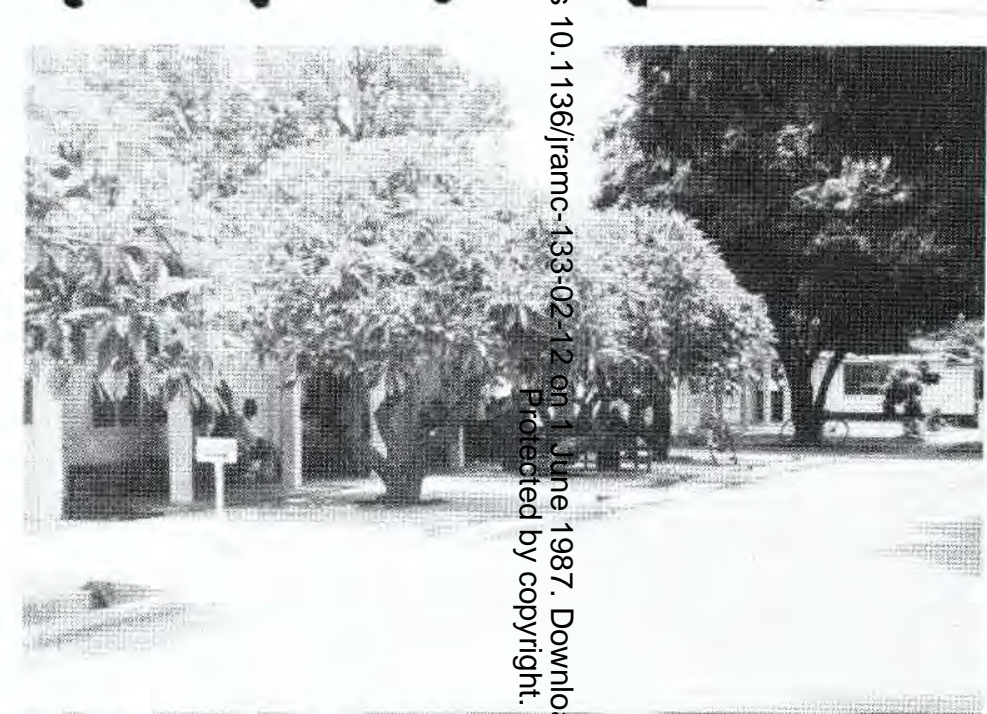

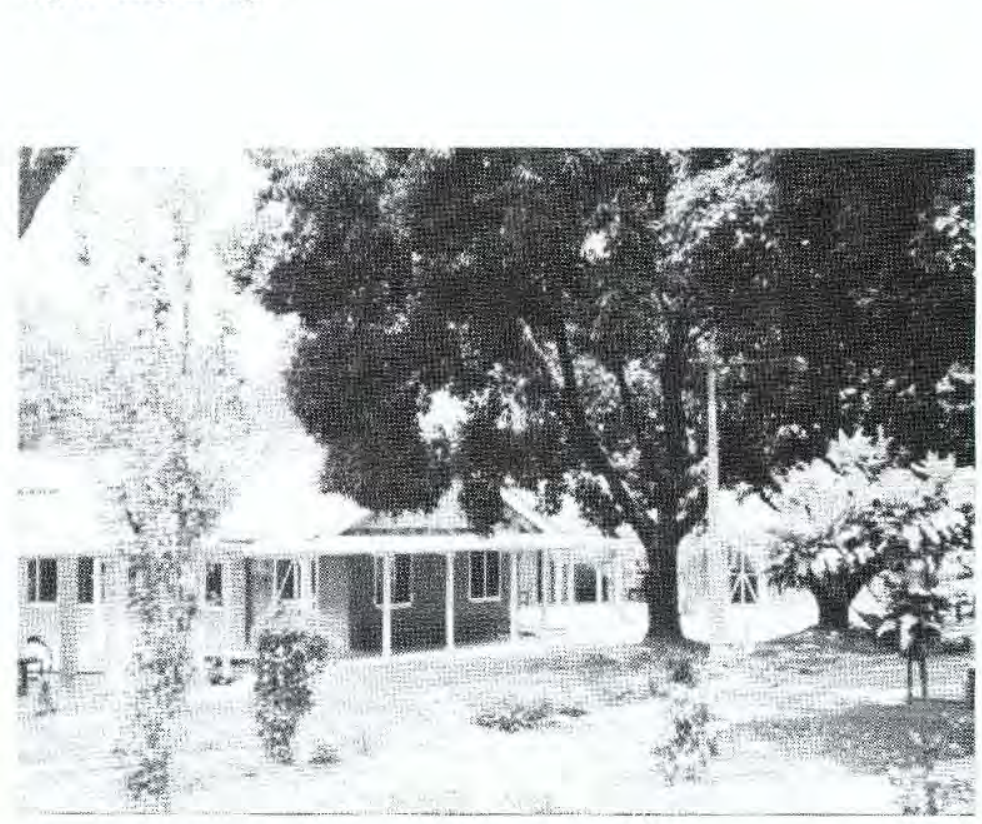

Fig. 3. BMH Dharan - TB and Minimal Care Wards

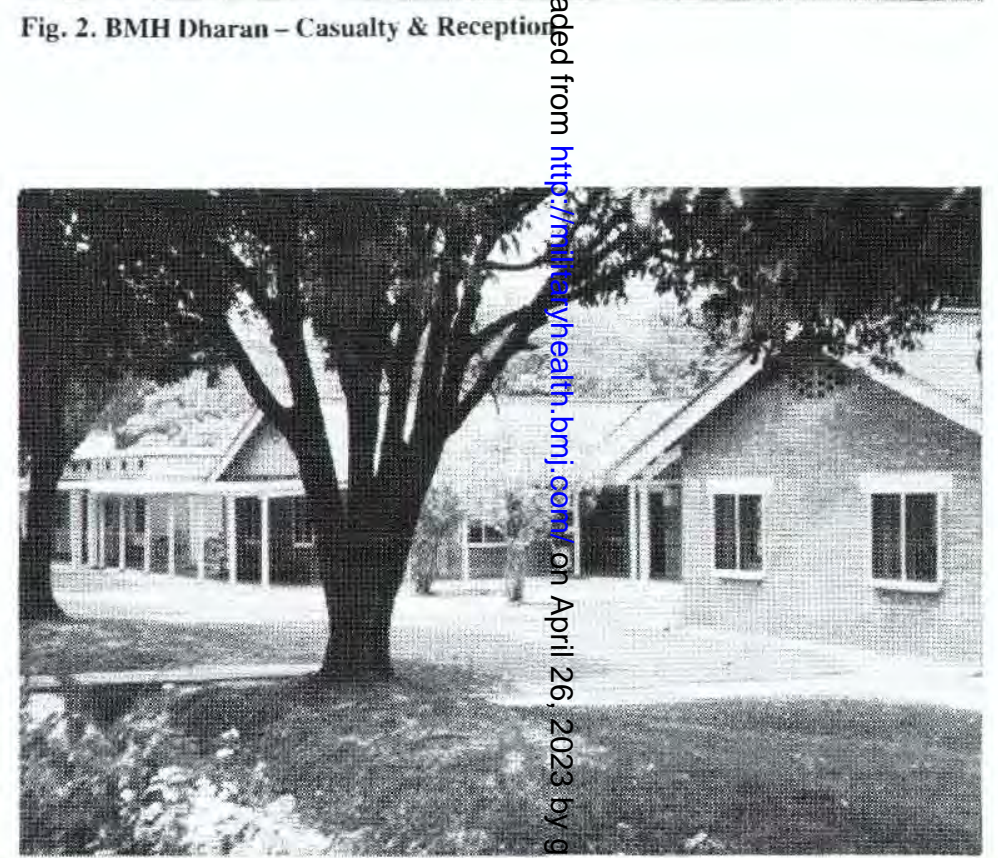

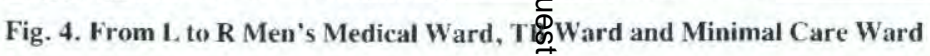


He described the difficulties of trying to produce a medical training scheme appropriate to the needs of the country, where unquestionably the main requirements at this stage are for community health and primary health care, with much less emphasis being laid on such things as expensive investigation techniques, renal dialysis or bone marrow transplantation. Potential medical students were chosen from para-medical workers, laboratory technicians, etc. Following qualification, these doctors are committed to scrvice in district hospitals for four years. To emphasise further the paramount importance of community health, any para-medic who has worked in the remoter areas for 3 years is much more likely to be accepted for medical training, assuming the necessary educational requirements have been met.

$\mathrm{He}$ also spoke of his work setting up the Physiology Department of the Medical School. He described the value of using everyday mechanical devices to demonstrate various aspects of physiology; to illustrate this he described a simple water supply from the top to the bottom of a hill with various intervening taps to control flow as an example of a negative feedback system.

\section{The End of the Road}

Mr Frank Guthrie, the Field Director of the British Nepal Medical Trust (BNMT) discussed the history of the Trust and the work it had done in East Nepal in the management of tuberculosis since its inception in the late 1960 s. His talk was illustrated by a videotape, "The End Of The Road", produced by BNMT, which described the work of its clinic in Chainpur, a small town about five days' walk north of Dharan.

Within the limitations imposed by the rugged terrain of the country with its inherent transport difficultics, and its lack of investigation facilities, the Trust has had a remarkable success in its primary aim, and has also played a large part in BCG vaccination in East Nepal.
It had been hoped to complement this talk by asking Dr Roy Welford, the Medical Director of Save the Children Fund (UK) in Dhankuta, to discuss the work of SCF in East Nepal. Unfortunately, because of staff problems, he was unable to attend.

\section{Japanese Encephalitis}

Since the first great interest in this disease in South East Nepal by Major Alan Henderson in 1982-83, a research project to quantify various aspects of the problem has been in progress organised by the Royal Army Medical College, the London School of Hygiene and Tropical Medicine and the U.S. Armed Forces Medical Research Institute in Bangkok.

A small epidemic of the disease occurred in South East Nepal in 1984, but in the monsoon period of 1985 the biggest epidemic so far of over 300 cases occurred. The initial results from these cases, attempts to isolate the virus in fatal cases, the collection of blood samples from sentinal pigs (considered then to be the amplifying host of the virus), and the various entomological aspects of the disease were discussed by DrC Leake, Virologist from the London School of Hygiene and Tropicti Medicine, by $\mathrm{Mr} \mathrm{K}$ Chetwyn, Entomologist from tho Royal Army Medical College and by Captain Bellamy, RAMC, Medical Officer to the project.

Dr Leake spoke with great enthusiasm about the larg number of positive results from CSF specimens from suspected cases. This hopefully would enable confio mation of the efficiency of the Biken vaccine against th disease. With guarded optimism for the futurc succe on this subject, the symposium closed after a very varied and interesting selection of lectures.

\section{Acknowledgements}

The author would like to express his gratitude to all speakers, guests and hospital staff for their great efforts in making this symposium so successful, and to Mrs Santamaya Rai who typed the manuscript, 